\title{
Therapeutic Effects of Curcumin on Toxicity Induced by Permethrin in Rat Liver and SK-Hep-1 Cells
}

\author{
Reza Abbasi Larki ${ }^{1(\mathbb{D})}$, Mohammad Heiat ${ }^{2(\mathbb{D})}$, Ehsan Zayerzadeh ${ }^{3, *(\mathbb{C})}$ \\ 1 Department of Microbiology, Karaj Branch, Islamic Azad University, Karaj, Iran; abbasi.reza.1984@ gmail.com (R.A.L.); \\ 2 Baqiyatallah Research Center for Gastroenterology and Liver Disease, Baqiyatallah University of Medical Sciences, \\ Tehran, Iran; mohamad.heiat@ gmail.com (M.H.); \\ 3 Department of Food Toxicology, Food Technology and Agricultural Products Research Center, Standard Research \\ Institute, Karaj, Iran; zayerzadeh@standard.ac.ir (E.Z.); \\ * Correspondence: zayerzadeh@standard.ac.ir;
}

Scopus Author ID 36117337300

Received: 10.09.2020; Revised: 5.11.2020; Accepted: 9.11.2020; Published: 15.11.2020

\begin{abstract}
This investigation aimed to evaluate the toxic effects of permethrin (PMN) on rat liver and the therapeutic efficacy of curcumin $(\mathrm{CMN})$ against PMN-induced alterations in hepatic biomarkers, liver antioxidant enzymes, and SK-Hep-1 cells. The animals were divided into four groups of six as follows: the first group was defined as the control, while the second, the third, and the fourth groups were orally treated with PMN (62.5 mg/kg bw), CMN (120 mg/kg bw), and PMN plus CMN, respectively for three weeks. Biochemical markers in the serum and the levels of lipid peroxidation (LPO) and antioxidant enzyme activity in the liver were determined. PMN exposure stimulated significant changes in animals' hepatic biomarkers, including alanine and aspartate aminotransferases (ALT and AST) and alkaline phosphatase (ALP). The results indicated that LPO was significantly raised in PMN-treated rats, as evidenced by high liver malondialdehyde (MDA) concentration. The antioxidant system in PMN-treated rats was altered, which confirmed by a significant decline $(\mathrm{p}<0.05)$ in the activity of catalase (CAT), glutathione peroxidase (GPX), and glutathione-S-transferase (GST) in the liver. On the other hand, the administration of CMN with PMN significantly $(\mathrm{p}<0.05)$ ameliorated ALT, AST, ALP, MDA, CAT, GPX, and GST activity. In addition, CMN demonstrated protective activity against toxicity induced by PMN in SK-Hep-1 cells. In conclusion, our findings demonstrated that PMN induced hepatic damage in rats and CMN had noticeable therapeutic effects on hepatic injuries, oxidative stress, and cytotoxicity induced by PMN.
\end{abstract}

Keywords: permethrin; curcumin; oxidative stress; hepatic biomarkers; liver; rat.

(C) 2020 by the authors. This article is an open-access article distributed under the terms and conditions of the Creative Commons Attribution (CC BY) license (https://creativecommons.org/licenses/by/4.0/).

\section{Introduction}

Globally, the pyrethroids are the most popular insecticides widely used as pest controllers [1]. The pyrethroids consist of two groups, including type I, such as permethrin (PMN), and type II, such as cypermethrin. PMN is the most popular among pyrethroids type I with a wide spectrum of insecticidal activity in the agricultural industry and vector controlling in public health and numerous veterinary parasites. Therefore, pyrethroids' exposure to humans, animals, and the environment is virtually inevitable [2]. Recently, investigations about the effects of pesticides on stress oxidative and antioxidant defense have grown in mammals [3]. Unfortunately, pyrethroids can induce oxidative stress in humans and animals, which results in toxicity. It was reported that PMN could induce apoptosis as well as lipid, protein, and DNA damage. It has also been suggested that oxidative stress may be an underlying 
mechanism for PMN toxicity [4]. Nowadays, it is evident that some plant products can mitigate the toxic effects induced by various toxicants such as pesticides in mammals $[5,6]$. These precious plants display their protective roles by scavenging free radicals and regulating the antioxidant defense system [5]. Curcumin (CMN) is a natural yellow pigment employed as a medicinal agent and as a spice and food-coloring agent in cooking. It owns a wide range of pharmacological properties. $\mathrm{CMN}$ has proved to inhibit inflammatory processes and perform as an antioxidant and anti-cancer agent $[7,8]$. Some studies have suggested that CMN could prevent oxidative stress induced by some materials such as gentamicin, acetaminophen, and arsenic in laboratory animals [9-11]. To the best of our knowledge, the protective role of CMN against possible toxic effects of PMN has not been investigated in rats. This study aimed to investigate the toxic effects of PMN on the liver rat and the therapeutic efficacy of CMN against $\mathrm{PMN}$-induced alterations in hepatic biomarkers, liver antioxidant enzymes, and SK-Hep-1 cells.

\section{Materials and Methods}

\subsection{Animals and materials.}

We obtained twenty-four adult male Wistar rats from the Razi Vaccine and Serum Institute of Iran. PMN (Pale yellow liquid; CAS No. 52645-53-1; purity $\geq 95 \%$ ) was purchased from Shanghai Bosman Industrial Co., Ltd. (China). Curcumin(CMN) was bought from Sigma Chemical Co. (St. Louis, France). Each rat was kept in a distinct cage to adapt to the lab environment before the experiment under standard and hygienic conditions (temperature of 22 $\pm 2{ }^{\circ} \mathrm{C}$, humidity $55 \pm 5 \%$, and a 12:12 light/dark cycle) with adequate standard laboratory food and water. Subsequent ten days of adaptation to the laboratory environment, the rats were separated into four groups. The recommendation of the animal care committee of Tehran University, the 'Guide for Care and Use of Laboratory Animals' (NIH US publication 86-23, revised 1985) was applied for the treatment of the animals.

\subsection{Experimental design.}

We suspended PMN and CMN in a sterile saline solution container. Twenty-four rats were randomly divided into four groups, six for each group. One group was selected as the saline control (first group), and the other groups were chosen as treatment groups. A single dose of PMN $(62.5 \mathrm{mg} / \mathrm{kg})$ was administered orally by gavage to the second group for 21 days. This dose corresponded to $1 / 20$ of the LD50 value of this pesticide [12]. A single-dose of CMN $(120 \mathrm{mg} / \mathrm{kg}$ ) was administered orally by gavage to the third group for 21 days. Finally, a single dose of CMN (120 mg/kg) plus a single dose of PMN $(62.5 \mathrm{mg} / \mathrm{kg})$ were simultaneously administered orally by gavage to the fourth group for 21 days.

\subsection{Tissue preparation.}

For the preparation of homogenates (10\%) of tissue, firstly, we homogenized $500 \mathrm{mg}$ of the liver in $2 \mathrm{ml}$ of buffer solution of phosphate-buffered saline (PBS by homogenizer under the ice-cold condition and centrifuged at $3000 \mathrm{rpm}$ for $15 \mathrm{~min}$ at $4{ }^{\circ} \mathrm{C}$. Then, the resultant supernatant was used for measuring malondialdehyde (MDA), catalase (CAT), glutathione peroxidase (GPX), and glutathione-S-transferase (GST) activity. 


\subsection{Analysis of oxidative stress and antioxidant parameters.}

According to the Shafiq et al. method for determining LPO level, we assessed MDA concentration in the liver [13]. GPX activity was evaluated by the method of Paglia and Valentine [14]. CAT activity was measured by the method of Aebi [15]. The activity of GST was evaluated by the method described by Habig et al. [16].

\subsection{Serum clinical chemistry parameters.}

We collected blood samples into test tubes containing EDTA, kept for $30 \mathrm{~min}$, and centrifuged at $3000 \mathrm{rpm}$ for $20 \mathrm{~min}$. Subsequently, we separated the serum samples and measured the concentrations of blood alanine aminotransferase (ALT), aspartate aminotransferase (AST), and alkaline phosphatase (ALP) by (Model BT3000 autoanalyzer Italy and commercial Biosystems kits, Spain) according to the manufacturer's instructions.

\subsection{Cell culture.}

We purchased the SK-Hep-1 cells from the Cell Bank of Pasteur Institute [3] and cultured in a minimum essential medium ( $\alpha$-MEM medium), supplemented with fetal bovine serum (10\%, v/v) and antibiotics (penicillin and streptomycin $1 \%$ ) at $37^{\circ} \mathrm{C}$ in a $5 \% \mathrm{CO} 2$ atmosphere with $95 \%$ humidity. After seeding the cells within the flask, they should be checked microscopically. The cell count was measured with a hemocytometer (Germany).

\subsection{Cytotoxicity analysis.}

[3-(4,5-Dimethylthiazol-2-yl)-2,5-Diphenyltetrazolium Bromide] (MTT) assay was performed for cell viability assessment and evaluation of cytotoxicity by converting mitochondrial dehydrogenases MTT into formazan crystals in living cells. For this purpose, we collected and cultured exponentially growing SK-Hep- 1 cells $\left(1 \times 10^{4}\right.$ cells/well $)$ in a 96-well microtiter plate and then incubated for 24 hours in a $5 \% \mathrm{CO}_{2}$ atmosphere before treatment. After reaching their confluency up to $70 \%$, the cells were treated with agents. A range of PMN and $\mathrm{CMN}$ concentrations $(5,50$, and $500 \mu \mathrm{M})$ were exposed with cells with $0.1 \%$ DMSO as the solvent control. The cells were also treated to a range of PMN and CMN concentrations (5, 50, and 500) simultaneously to study cytotoxicity. After treatment for 24 hours, $100 \mu \mathrm{L}$ of MTT solution $(0.5 \mathrm{mg} / \mathrm{mL})$ was added to each well and incubated at $37^{\circ} \mathrm{C}$ for three hours. The supernatants were then removed, and $100 \mu \mathrm{L}$ of DMSO was added to each well to solubilize the formed formazan crystals [17, 18]. A plate spectrophotometer (BioTek, USA) was applied to read absorbance at $570 \mathrm{~nm}$.

\subsection{Statistical analysis.}

All data have been represented as mean \pm SEM. The mean of all parameters between the two groups was compared using one-way ANOVA. Data were analyzed by SPSS software (version 19) with a $\mathrm{p}<0.05$ being considered statistically significant. 


\section{Results and Discussion}

\subsection{Clinical symptoms and body weight.}

Clinical symptoms such as depression, head shaking, and ataxia in animals treated with PMN were induced. However, any clinical signs in the curcumin (CMN) group's animals were not observed, although in the fourth group treated with PMN plus CMN, mild ataxia and head shaking were observed. Also, there was no mortality in any of the groups. After the administration of PMN, means of body weight of animals, it was significantly reduced. This index in the third group of animals did not show significant alterations compared to the control group. The administration of CMN plus PMN improved rats' body weight compared to the second group (Table 1).

Table 1. Effect of permethrin (PMN), curcumin, and PMN plus curcumin (CMN) on rats' body weight; Values are given as means \pm SEM for six animals in each group. Significantly different from control group (*; $\mathrm{P}<0.05)$; significantly different from PMN group (**; $\mathrm{P}<0.05$ ).

\begin{tabular}{l|c|c} 
Groups & Bodyweight $(\mathbf{g})$ on the first day & Bodyweight (g) on the last day \\
\hline Control & $205 \pm 19$ & $380 \pm 32$ \\
\hline PMN & $208 \pm 21$ & $298 \pm 25^{*}$ \\
\hline curcumin & $210 \pm 18$ & $391 \pm 34$ \\
\hline PMN + curcumin & $205 \pm 21$ & $348 \pm 33^{* *}$
\end{tabular}

\subsection{Serum biochemical enzymes.}

AST, ALT, and ALP levels were significantly $(\mathrm{p}<0.05)$ raised in PMN-treated animals compared to the control group. However, significant changes were not induced in these biochemical parameters in the CMN-treated animals. Furthermore, the co-administration of CMN with PMN significantly modulated AST, ALT, and ALP concentrations in the serum (Figure 1).

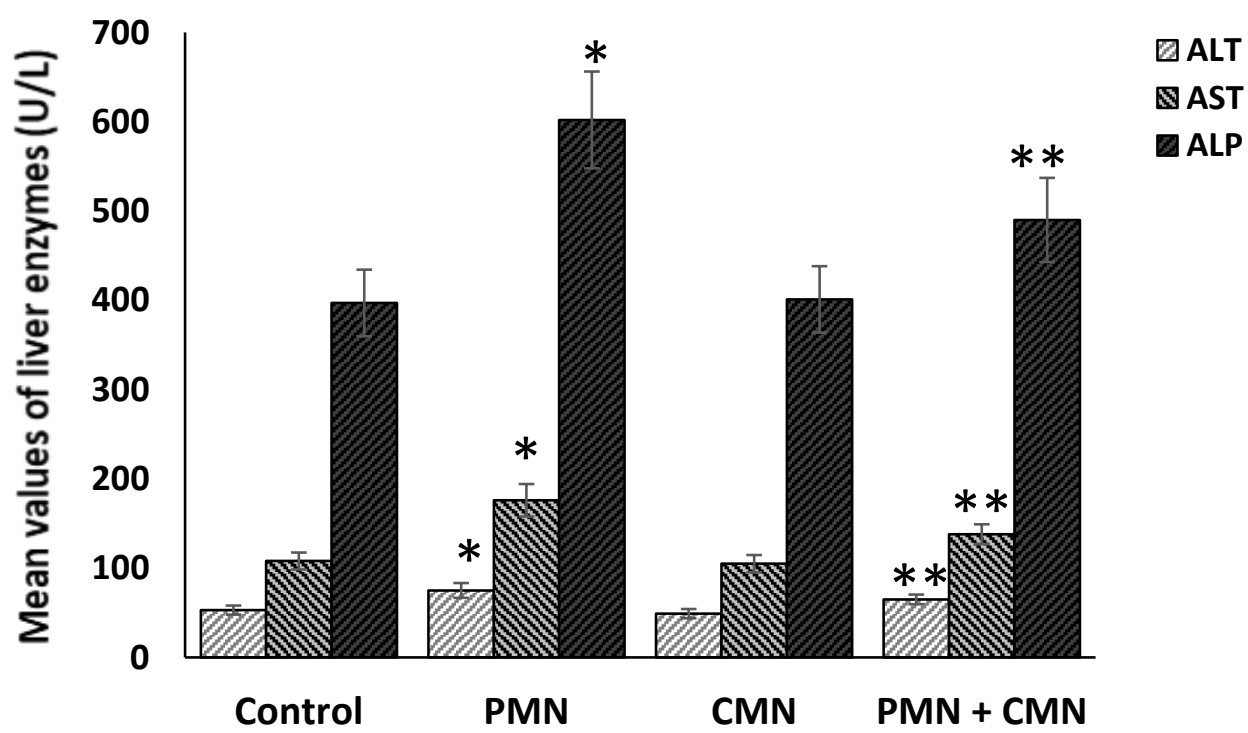

Figure 1. Effect of permethrin (PMN), curcumin (CMN) and PMN plus CMN on the blood concentrations of ALT, AST, and ALP in rats; Values are given as means \pm SEM for six animals in each group. Significantly different from control group (*; $\mathrm{P}<0.05)$; significantly different from PMN group (**; $\mathrm{P}<0.05)$.

\subsection{Effects on MDA.}

The effects on MDA concentration in the liver are presented in Figure 2. A significant rise $(p<0.05)$ was observed in MDA in the liver after PMN exposure in the second group. MDA 
level was not changed in curcumin-treated rats. On the other hand, simultaneous oral administration of CMN with PMN ameliorated MDA disturbances in the liver tissue.

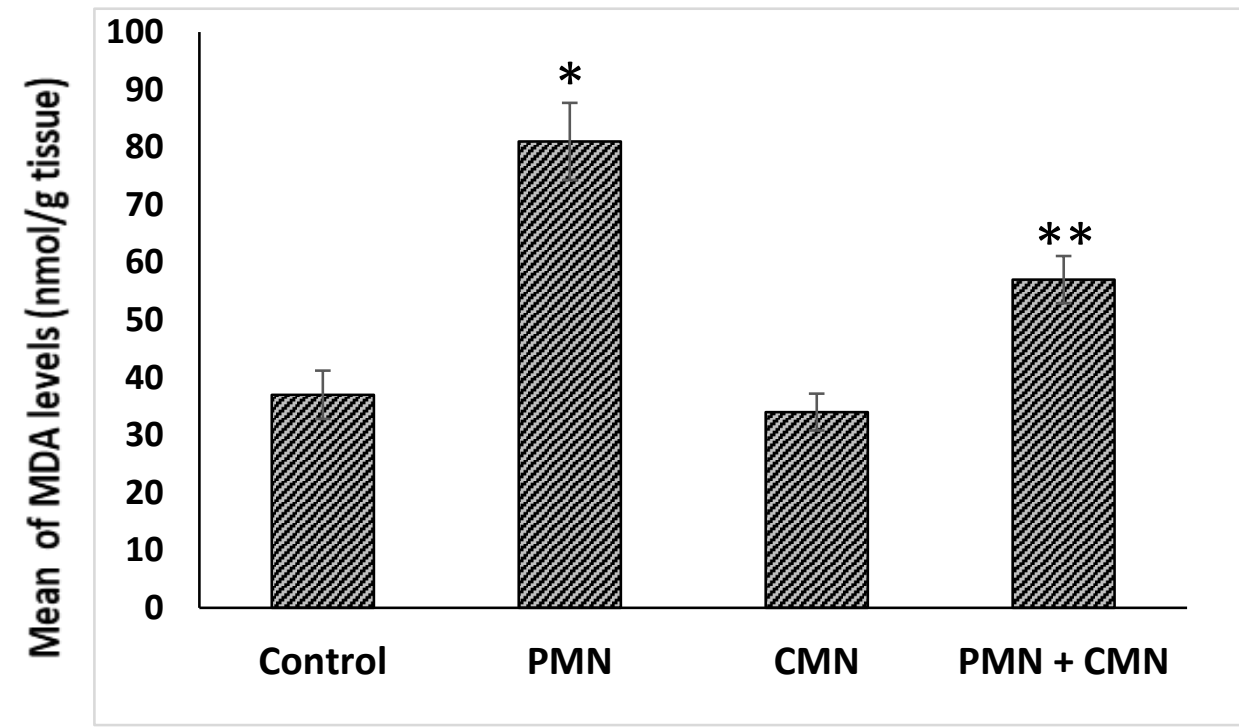

Figure 2. Effect of permethrin (PMN), curcumin $(\mathrm{CMN})$ and PMN plus CMN on MDA levels of the liver in rats; Values are given as means \pm SEM for six animals in each group; Significantly different from the control group; $(* ; \mathrm{P}<0.05)$; significantly different from PMN group $(* * ; \mathrm{P}<0.05)$.

\subsection{Effects on antioxidant enzyme activity.}

A significant decline ( $\mathrm{p}<0.05$ ) was induced in CAT, GST, and GPX activity in the PMN-treated group compared to the control group. Co-administration of CMN with PMN significantly improved the GPX, CAT, and GST activities compared to the PMN-treated group. Antioxidant enzyme activity was not complicated in CMN-treated animals (Figures 3, 4, and $5)$.

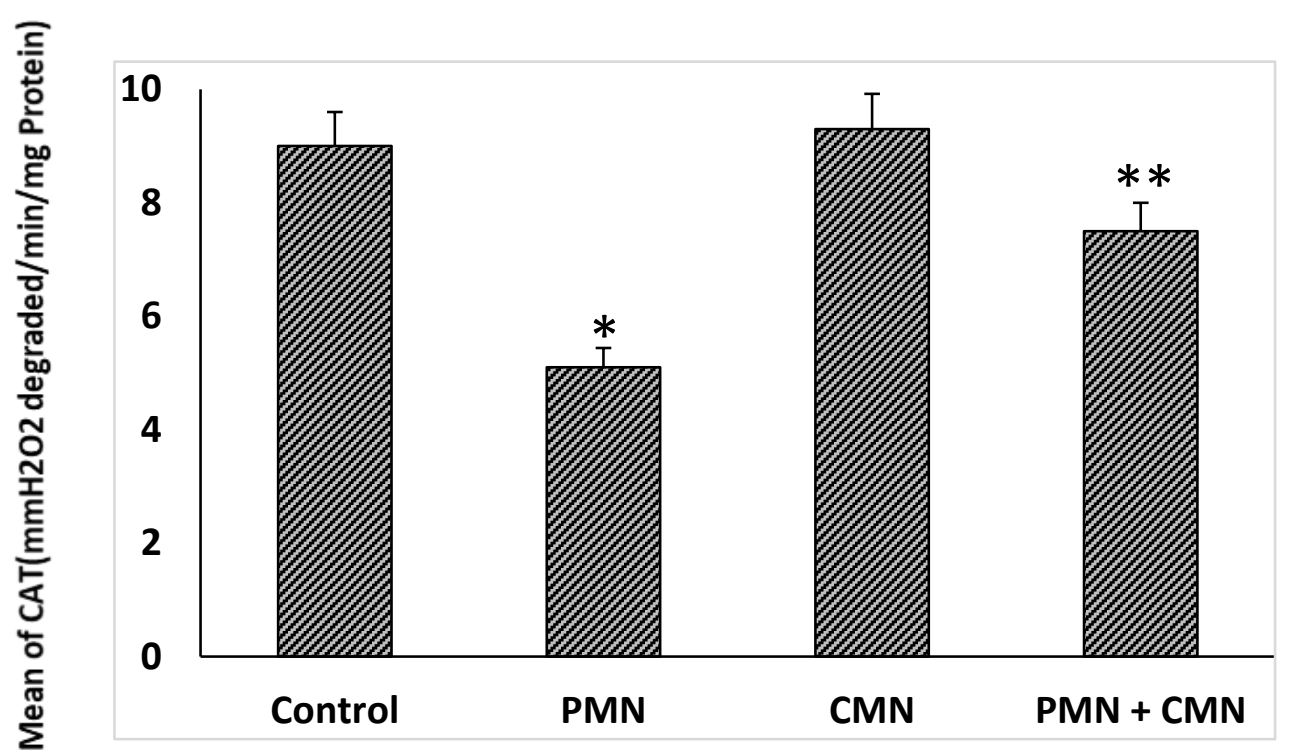

Figure 3. Effect of permethrin (PMN), curcumin (CMN), and PMN plus CMN on the liver's CAT activity in rats; Values are given as means \pm SEM for six animals in each group. Significantly different from control group (*; $\mathrm{P}<0.05)$; significantly different from PMN group $(* * ; \mathrm{P}<0.05)$. 


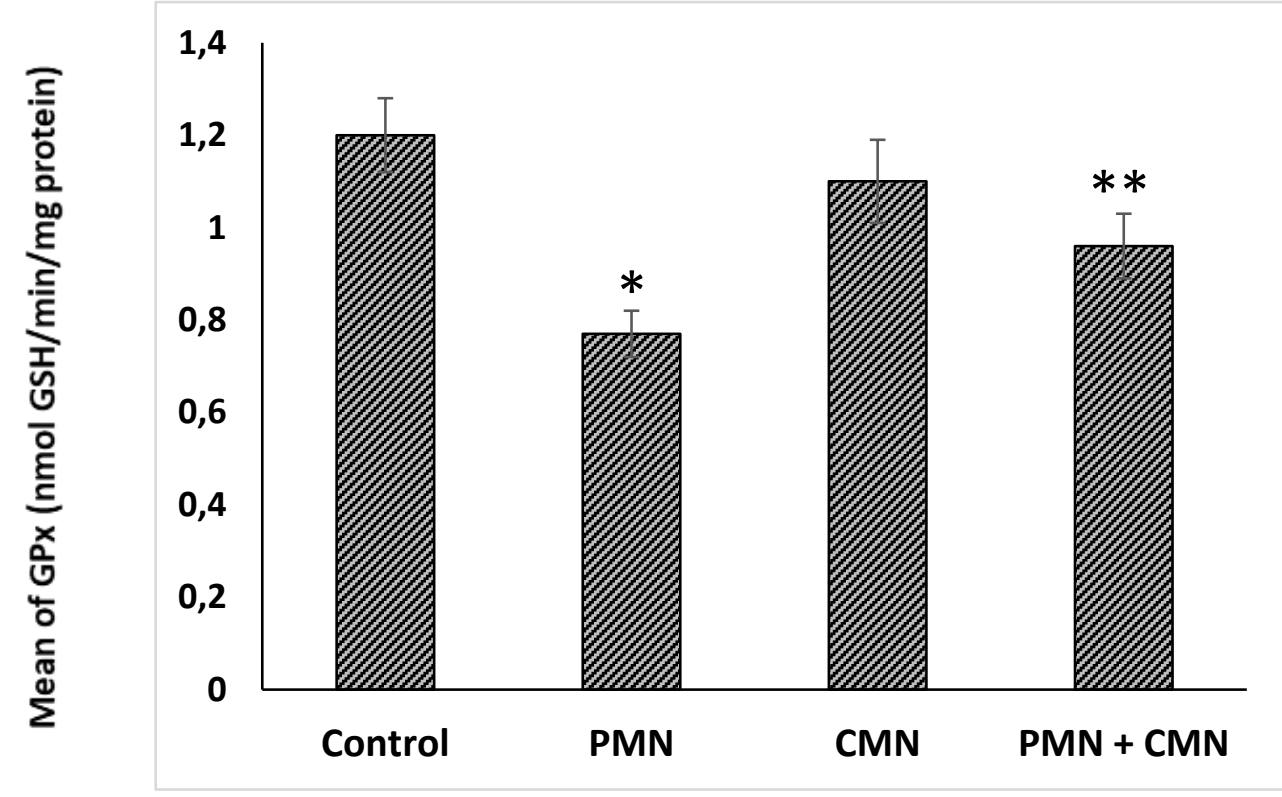

Figure 4. Effect of permethrin (PMN), curcumin (CMN), and PMN plus CMN on GPX activity of the liver in rats; Values are given as means \pm SEM for six animals in each group. Significantly different from control group (*; $\mathrm{P}<0.05)$; significantly different from PMN group (**; $\mathrm{P}<0.05)$.

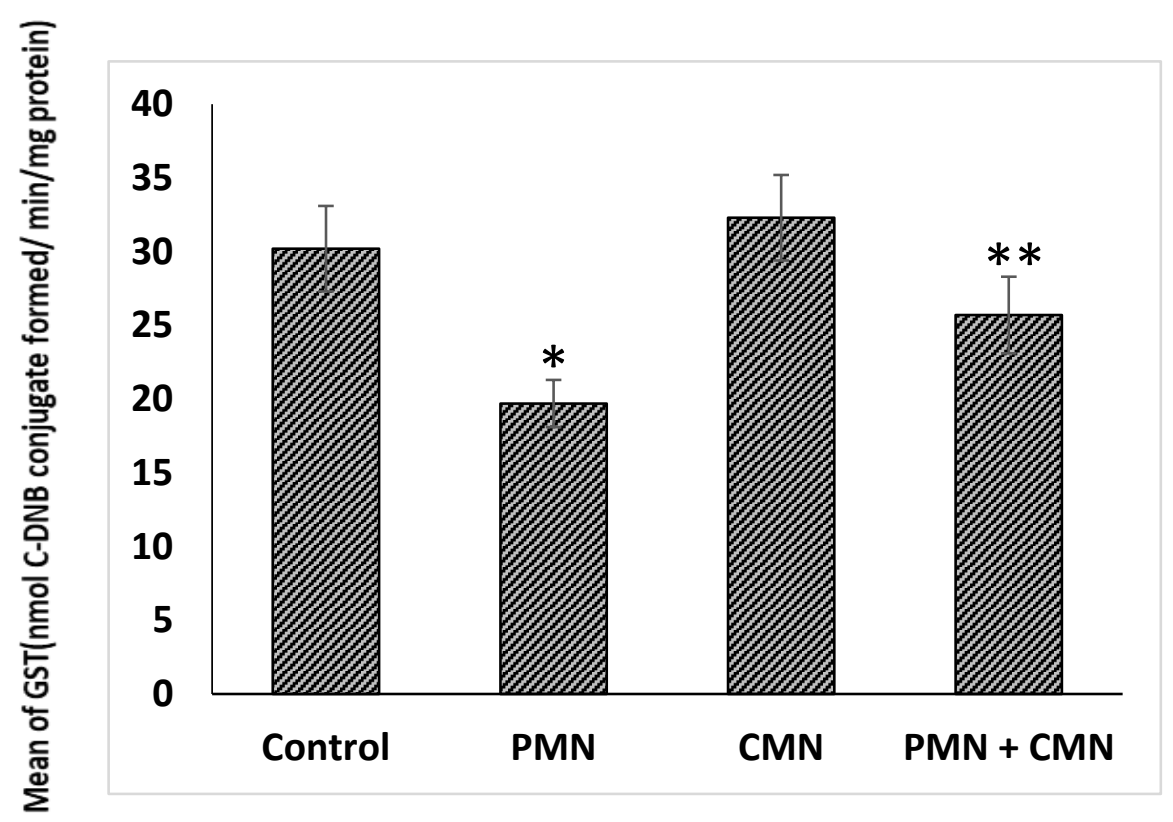

Figure 5. Effect of permethrin (PMN), curcumin (CMN), and PMN plus CMN on GST activity of the liver in rats; Values are given as means \pm SEM for six animals in each group. Significantly different from control group (*; $\mathrm{P}<0.05)$; significantly different from PMN group (**; $\mathrm{P}<0.05)$.

\subsection{Cytotoxicity analysis.}

The viability of SK-Hep-1 cells was significantly declined when treated with a range of PMN ( $\mathrm{P}<0.05)$. PMN did not induce any significant cytotoxic effects at a concentration of $5 \mu \mathrm{M}$ for 24 hours but reduced viability to $78 \pm 3 \%$ and $43 \pm 2 \%$ at $50 \mu \mathrm{M}$ and $500 \mu \mathrm{M}$, respectively. On the other hand, $\mathrm{CMN}$ did not induce any significant cytotoxicity at any of the concentrations. In the CMN plus PMN group, the survival rate was significantly improved compared to the PMN-treated cells $(\mathrm{P}<0.05)$ (Figure 6). 


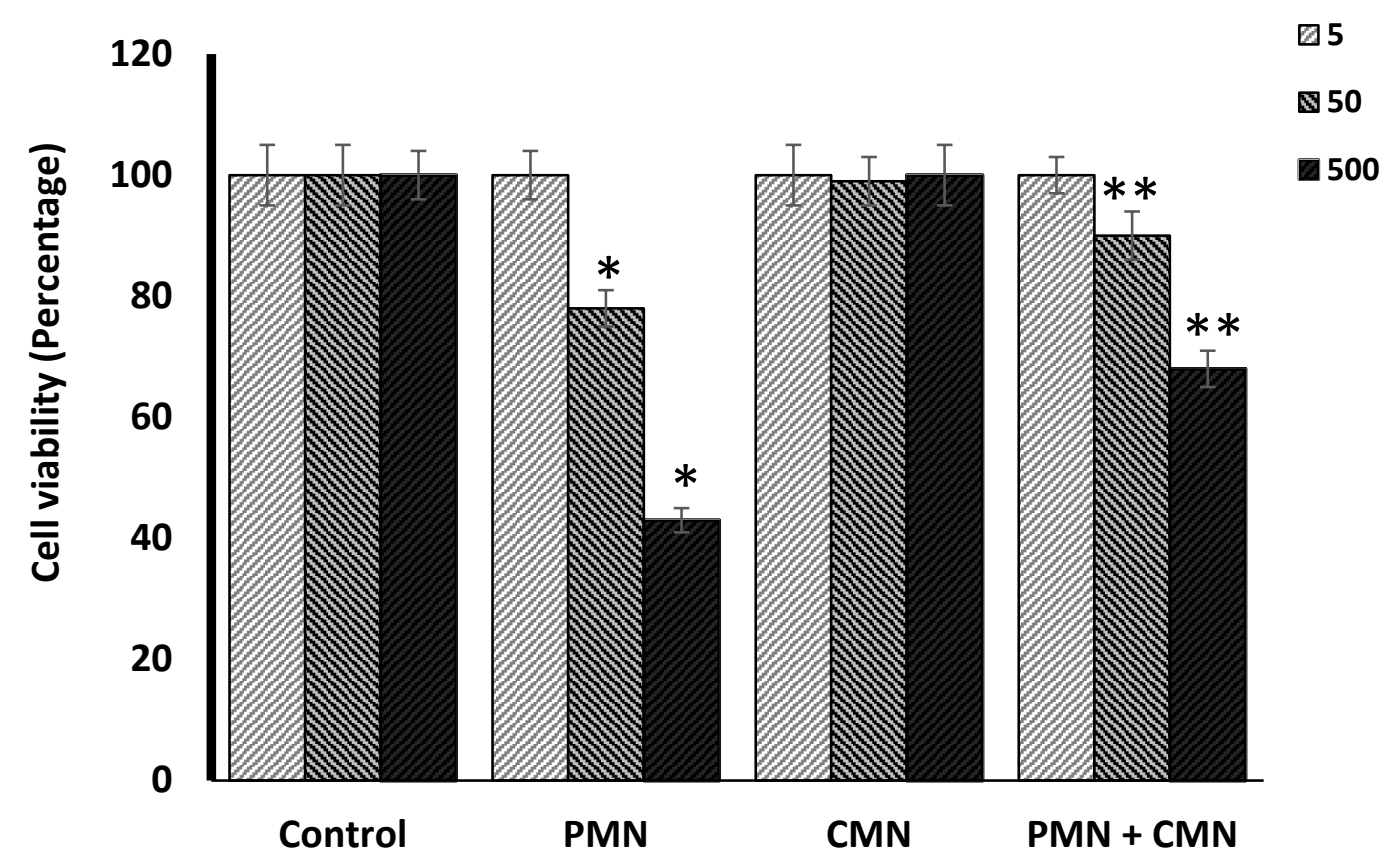

Figure 6. Effect of different doses of permethrin (PMN), curcumin (CMN) and CMN plus PMN on the viability of the SK-Hep-1 cell line. Values were given asmeans \pm SEM. Significantly different from control group (*P $<$ $0.05)$; significantly different from PMN group $(* * \mathrm{P}<0.05)$.

Antioxidant enzymes protect living organisms against toxic impacts induced by reactive oxygen species (ROS) through oxidation/reduction processes [19]. Our results demonstrated that PMN decreased the number of antioxidant enzymes, including CAT, GST, and GPX, in the liver of treated animals. In agreement with our results, following treatment of rats with PMN $(300 \mathrm{mg} / \mathrm{kg}$ ) for 22 days, it dropped GPX and CAT levels [20]. PMN induced oxidative stress could be shown by the decreased intracellular concentration of CAT, GST, and GPX. Subsequently, insufficient antioxidant defense or overproduction of free radicals could cause oxidative stress. Our findings are adopted with the findings of some surveys discovering that PMN reduced the concentration of CAT and GPX in rats [21, 22]. CAT is a hydroxyl ion scavenger that reduces hydrogen peroxide to molecular oxygen and water. Based on previous studies, LPO might be a cooperating factor for the decline in the catalase activity during pyrethroid toxicity [23]. GPX and other glutathione-related enzymes could have an antioxidant impact either directly or indirectly. We could reduce this enzyme activity, which emulates perturbations in normal oxidative mechanisms during PMN toxicity. Oxidative stress might lead to significant lipid peroxidation of lipids in the cell membrane, where lipid peroxidation can be assessed by investigating alterations in MDA and thiobarbituric acid reacting substances (TBARS). The findings of our study showed an increased level of MDA in the liver following the administration of PMN in the treated rats. Boosted MDA in the liver is an indicator of LPO induced by this pesticide. LPO has been considerably applied as a marker of oxidative stress. Pyrethroid exposure has been demonstrated to reduce membrane fluidity, thereby boosting LPO [20]. In a study by Gabbianelli et al., it was found that treating with PMN $(34.05 \mathrm{mg} / \mathrm{kg}$ could induce a significant rise in lipid peroxidation compared to the control group [24]. Additionally, treatment with various dosage ranges of PMN in rats resulted in MDA rise after 45 or 60 days [25].

In our study, the simultaneous treatment with CMN and PMN ameliorated the PMNinduced reduction in the CAT, GST, and GPX activity in the liver of treated animals. CMN has been reported to restore CAT levels and GPX during cypermethrin induced toxicity in rats [26]. 
Elsewhere, TBARS concentration in the liver was significantly boosted in diazinon-treated rats [27]. On the other hand, in our study, there was a significant decline in the MDA level in PMN plus CMN treated group as compared to PMN treated group. These results are in line with previous studies [26]. Our observations are also compatible with the findings of a study suggesting that the administration of CMN plus cypermethrin improved antioxidant enzymes' perturbations and cypermethrin-induced oxidative stress in rats. Co-administration of CMN and cypermethrin led to decreased elevated tissue LPO in the liver, kidney, and brain tissues $[26,28]$. The supplementation of vitamin $\mathrm{E}$ and/or CMN ameliorated lipid peroxidation, caused by diazinon exposure, significantly regulated the liver's TBARS levels [27]. It has been shown that CMN could regulate various biochemical pathways and numerous types of signaling components, including adhesion and inflammatory molecules, transcription, growth factors, protein kinases, protein reductases, cell-cycle regulatory proteins, and many enzymes [29]. CMN can scavenge various sorts of free radicals, including reactive oxygen and nitrogen species [30, 31]. It also has a unique structure with phenolic hydroxyl and methoxy-groups responsible for radical scavenging activity and a central methylene moiety capable of $\mathrm{H}$-atom donation and breaking chain oxidation reaction [32 - 35]. In the present study, subsequent to oral administration of PMN in rats, the level of ALT, AST, and ALP was significantly elevated. AST and ALT are essential biomarkers in the diagnosis of liver disorders in combination with other markers. A significant increment of serum ALP level is usually noticed in liver damage [36]. The findings of our study demonstrated that exposure to PMN induced hepatotoxicity, given the significant elevation of AST, ALT, and ALP activity in experimental rats, probably due to cellular injury of the liver tissues. Our results are consistent with a report's findings demonstrating that cypermethrin could induce liver and kidney failure. These surveys' findings reported the elevation of biomarkers, including ALT and AST, following cypermethrin (25 $\mathrm{mg} / \mathrm{kg}$ ) oral administration in rats after four weeks [26].

On the other hand, the simultaneous administration of CMN ameliorated the permethrin-induced changes in the concentrations of hepatic parameters in the present study. $\mathrm{CMN}$ offers its protective effect by regulating the hepatic marker enzymes. The modification in the concentration of liver markers by $\mathrm{CMN}$ observed in our study is compatible with previous studies $[26,37]$. The results of our cytotoxicity evaluation indicated that PMN was highly cytotoxic for SK-Hep-1 cells. On the other hand, not only did CMN cause any significant cytotoxic effects at any of the concentrations, but it also ameliorated cytotoxic impacts induced with PMN in SK-Hep-1 cells.

\section{Conclusions}

In conclusion, the present investigation findings suggested that PMN could induce oxidative stress and lipid peroxidation in the liver of rats. Our results also demonstrate that $\mathrm{CMN}$ has an inhibitory effect against PMN-induced lipid peroxidation, oxidative stress, biochemical alterations in the rats, and cytotoxicity in SK-Hep-1 cells. It seems that antioxidant activity might result in its curative performance property. Therefore, CMN should be beneficial as a pharmacological agent for ameliorating oxidative damages.

\section{Funding}

The Standard Research Institute funded this research. 


\section{Acknowledgments}

We acknowledge all supports given by colleagues at Standard Research Institute.

\section{Conflicts of Interest}

The authors declare no conflict of interest.

\section{References}

1. Chrustek, A.; Hołyńska-Iwan, I.; Dziembowska, I.; Bogusiewicz, J.; Wróblewski, M.; Cwynar, A.; Olszewska-Słonina, D. Current research on the safety of pyrethroids used as insecticides. Medicina (Lithuania) 2018, 54, https://doi.org/10.3390/medicina54040061.

2. Nasuti, C.; Cantalamessa, F.; Falcioni, G.; Gabbianelli, R. Different effects of type I and type II pyrethroids on erythrocyte plasma membrane properties and enzymatic activity in rats. Toxicology 2003, 191, 233-44, https://doi.org/10.1016/S0300-483X(03)00207-5.

3. Zini, A.; de Lamirande, E.; Gagnon, C. Reactive oxygen species in semen of infertile patients: levels of superoxide dismutase- and catalase-like activities in seminal plasma and spermatozoa. International Journal of Andrology 1993, 16, 183-188, https://doi.org/10.1111/j.1365-2605.1993.tb01177.x.

4. Wang, X.; Martínez, M.A.; Dai, M.; Chen, D.; Ares, I.; Romero, A.; Castellano, V.; Martínez, M.; Rodríguez, J.L.; Martínez-Larrañaga, M.R.; Anadón, A.; Yuan, Z. Permethrin-induced oxidative stress and toxicity and metabolism. A review. Environ Res 2016, 149, 86-104, https://doi.org/10.1016/j.envres.2016.05.003.

5. Qin, S.; Huang, L.; Gong, J.; Shen, S.; Huang, J.; Tang, Y.; Ren, H.; Hu, H. Meta-analysis of randomized controlled trials of 4 weeks or longer suggest that curcumin may afford some protection against oxidative stress. Nutr Res 2018, 60, 1-12, https://doi.org/10.1016/j.nutres.2018.08.003.

6. Lushchak, V.I.; Matviishyn, T.M.; Husak, V.V.; Storey, J.M.; Storey, K.B. Pesticide toxicity: a mechanistic approach. J EXCLI 2018, 17, https://doi.org/10.17179/excli2018-1710.

7. Biswas, S.K.; McClure, D.; Jimenez, L.A.; Megson, I.L.; Rahman, I. Curcumin induces glutathione biosynthesis and inhibits NF- $\mathrm{kB}$ activation and interleukin-8 release in alveolar epithelial cells: Mechanism of free radical scavenging activity. Antioxid Redox Signal 2005, 7, 32-41, https://doi.org/10.1089/ars.2005.7.32.

8. Reddy, A.C.P.; Lokesh, B.R. Studies on the inhibitory effects of curcumin and eugenol on the formation of reactive oxygen species and the oxidation of ferrous iron. Mol Cell Biochem 1994, 137, 1-8, https://doi.org/10.1007/BF00926033.

9. Cekmen, M.; Ilbey, Y.O.; Ozbek, E.; Simsek, A.; Somay, A.; Ersoz, C. Curcumin prevents oxidative renal damage induced by acetaminophen in rats. Food Chem Toxicol 2009, 47, 1480-84, https://doi.org/10.1016/j.fct.2009.03.034.

10. El-Demerdash, F.M.; Yousef, M.I.; Radwan, F.M.E. Ameliorating effect of curcumin on sodium arseniteinduced oxidative damage and lipid peroxidation in different rat organs. Food Chem Toxicol 2009, 47, 24954, https://doi.org/10.1016/j.fct.2008.11.013.

11. Farombi, E.O.; Ekor, M. Curcumin attenuates gentamicin-induced renal oxidative damage in rats. Food Chem Toxicol 2006, 44, 1443-48, https://doi.org/10.1016/j.fct.2006.05.005.

12. Cantalamessa, F. Acute toxicity of two pyrethroids, permethrin, and cypermethrin in neonatal and adult rats. Arch Toxicol 1993, 67, 510-13, https://doi.org/10.1007/BF01969923.

13. Shafiq-ur-Rehman; Rehman, S.; Chandra, O.; Abdulla, M. Evaluation of malondialdehyde as an index of lead damage in rat brain homogenates. Biometals 1995, 8, 275-79, https://doi.org/10.1007/BF00141599.

14. Paglia, D.E.; Valentine, W.N. Studies on the quantitative and qualitative characterization of glutathion proxidase. J Lab Clin Med 1987, 70, 158-65.

15. Aebi, H. Catalase in Vitro. Methods Enzymol 1984, 105, 121-6, https://doi.org/10.1016/S00766879(84)05016-3.

16. Habig, W.H.; Pabst, M.J.; Jakoby, W.B. Glutathione S transferases. The first enzymatic step in mercapturic acid formation. J Biol Chem 1974, 249, 7130-9.

17. Soufdoost, R.S.; Yazdanian, M.; Tahmasebi, E.; Yazdanian, A.; Tebyanian, H.; Karami, A.; Nourani, M.R.; Panahi, Y. In vitro and in vivo evaluation of novel Tadalafil/ $\beta$-TCP/Collagen scaffold for bone regeneration: A rabbit critical-size calvarial defect study. Biocybern Biomed Eng 2019, 39, 789-796, https://doi.org/10.1016/j.bbe.2019.07.003.

18. Seifi Kafshgari, H.; Yazdanian, M.; Ranjbar, R.; Tahmasebi, E.; Mirsaeed, S.; Tebyanian, H.; Ebrahimzadeh, M.A.; Goli, H.R. The effect of Citrullus colocynthis extracts on Streptococcus mutans, Candida albicans, normal gingival fibroblast and breast cancer cells. $J$ Biol Res 2019, 92, 8201, https://doi.org/10.4081/jbr.2019.8201.

19. Yang, H.Y.; Lee, T.H. Antioxidant enzymes as redox-based biomarkers: A brief review. BMB Rep 2015, 48, 200-8, https://doi.org/10.5483/BMBRep.2015.48.4.274.

https://biointerfaceresearch.com/ 
20. Gabbianelli, R.; Nasuti, C.; Falcioni, G.; Cantalamessa, F. Lymphocyte DNA damage in rats exposed to pyrethroids: Effect of supplementation with Vitamins E and C. Toxicology 2004, 203, 17-26, https://doi.org/10.1016/j.tox.2004.05.012.

21. El-Demerdash, F.M. Oxidative stress and hepatotoxicity induced by synthetic pyrethroids-organophosphate insecticides mixture in rat. J Environ Sci Health C Environ Carcinog Ecotoxicol Rev 2011, 29, 145-58, https://doi.org/10.1080/10590501.2011.577679.

22. Nasuti, C.; Falcioni, M.L.; Nwankwo, I.E.; Cantalamessa, F.; Gabbianelli, R. Effect of permethrin plus antioxidants on locomotor activity and striatum in adolescent rats. Toxicology 2008, 251, 45-50, https://doi.org/10.1016/j.tox.2008.07.049.

23. Ateşşahin, A.; Yilmaz, S.; Karahan, I.; Pirinçci, I.; Taşdemir, B. The effects of vitamin E and selenium on cypermethrin-induced oxidative stress in rats. Turk J Vet Anim Sci 2005, 29, 385-91.

24. Gabbianelli, R.; Palan, M.; Flis, D.J.; Fedeli, D.; Nasuti, C.; Skarydova, L.; Ziolkowski, W. Imbalance in redox system of rat liver following permethrin treatment in adolescence and neonatal age. Xenobiotica 2013, 43, 1103-10, https://doi.org/10.3109/00498254.2013.796427.

25. Issam, C.; Zohra, H.; Monia, Z.; Hassen, B.C. Effects of dermal sub-chronic exposure of pubescent male rats to permethrin (PRMT) on the histological structures of genital tract, testosterone and lipoperoxidation. Exp Toxicol Pathol 2011, 63, 393-400, https://doi.org/10.1016/j.etp.2010.02.016.

26. Sankar, P.; Telang, A.G.; Manimaran, A. Protective effect of curcumin on cypermethrin-induced oxidative stress in Wistar rats. Experimental and Toxicologic Pathology 2012, 64, 487-493, https://doi.org/10.1016/j.etp.2010.11.003.

27. Messarah, M.; Amamra, W.; Boumendjel, A.; Barkat, L.; Bouasla, I.; Abdennour, C.; Boulakoud, M.S.; Feki, A.E. Ameliorating effects of curcumin and vitamin E on diazinon-induced oxidative damage in rat liver and erythrocytes. Int J Androl 2013, 29, 77-88, https://doi.org/10.1177/0748233712446726.

28. Eybl, V.; Kotyzova, D.; Koutensky, J.; Leseticky, L. Effect of copper (II)-curcumin complex and curcumin on cadmium-induced oxidative damage and essential elements status in mice. J Toxicology Letters 2006, S193, https://doi.org/10.1016/j.toxlet.2006.07.059.

29. Shehzad, A.; Khan, S.; Sup Lee, Y. Curcumin molecular targets in obesity and obesity-related cancers. Future Oncol 2012, 8, 179-90, https://doi.org/10.2217/fon.11.145.

30. Menon, V.P.; Sudheer, A.R. Antioxidant and anti-inflammatory properties of curcumin. Adv. Exp. Med. Biol 2007, 595, 105-125, https://doi.org/10.1007/978-0-387-46401-5_3.

31. Kotha, RR.; Luthria, DL.; Molecules. Curcumin: Biological, Pharmaceutical, Nutraceutical, and Analytical Aspects. Molecules 2019 13;24(16):2930. doi: 10.3390/molecules24162930.

32. Marchiani, A.; Rozzo, C.; Fadda, A.; Delogu, G.; Ruzza, P. Curcumin and Curcumin-like Molecules: From Spice to Drugs. Curr Med Chem 2013, 21, 204-22, https://doi.org/10.2174/092986732102131206115810.

33. Giordano, A.; Tommonaro G. Curcumin and Cancer. Nutrients 2019, 5, 2376, https://doi.org/10.3390/nu11102376.

34. Bhat, A.; Mahalakshmi, AM.; Ray, B.; Tuladhar, S.; Hediyal, TA.; Manthiannem E.; Padamati, J.; Chandra, R.; Chidambaram, SB.; Sakharkar, MK. Benefits of curcumin in brain disorders. Biofactors 2019, 45, 666689, https://doi.org/10.1002/biof.1533.

35. Yang, M.; Akbar, U.; Mohan, C. Curcumin in Autoimmune and Rheumatic Diseases. Nutrients 2019, 11, 1004, https://doi.org/10.3390/nu11051004.

36. Mahna, D.; Puri, S.; Sharma, S.J.T.F.J. Cypermethrin Induced Liver Toxicity: Altered Gene Expression and DNA Methylation. The Faseb Journal 2019, 33, 621.9-621.9.

37. Tirkey, N.; Kaur, G.; Vij, G.; Chopra, K. Curcumin, a diferuloylmethane, attenuates cyclosporine-induced renal dysfunction and oxidative stress in rat kidneys. BMC Pharmacol 2005, 5, https://doi.org/10.1186/14712210-5-15. 